\title{
Discussion on Digital Development and Reuse of Teacher's Professional Archives in Network Era
}

\author{
Aitang Zuo \\ Feixian Campus of Linyi University, Feixian County, Linyi, Shandong Province, China \\ fsz006@126.com
}

Keywords: Internet Era; Teacher Tasks; Archives; Digitalization

\begin{abstract}
Digital development is the necessary way of archives management. Digital archives has its rules and requirements, which should be abided by teachers in their professional archives digitization development. The recycling of professional development of archives digitalization mainly reflects in: the development and use of academic background structure of teachers; information exploration of learning and knowledge capability as well as the establishment research of dominant disciplines; information development of age structure of teachers and research on elites in the new century; obvious information development and digital transformation of achievements.
\end{abstract}

\section{Introduction}

With the rapid development of information technology, network has involved in every aspect of social life, especially that the application of information technology in archives management has accelerated the development of theoretical research of networked archives and some achievements have been made from it. Research on the regularity of adopting teaching archives, an important educational resource, into network is a significant aspect of the achievements.

\section{Inexorable Law for the Formation of Digital Archives}

Digital archives itself is obtained from the conversion of electronic documents. After the documents sorted well and environmental requirement are saved to magnetic memory carrier or disc, they will be converted to digital archives. [1]The regularity of formation of digital archives mainly includes three aspects:

Inner Requirement of Converting Electronic Documents into Digital Archives. In human social activities, people usually tend to use documents as a tool of ideographical expression to realize certain objective purpose and extend their cognitive, managerial and control capacity for the object in social activity. People used paper documents a lot in the past, but now depend on electronic ones more. It is necessary to conduct effective management on both paper and electronic documents in order to protect information security for future review and reference. Only when these documents are converted into archives, they can play a role in information exchange in a longer period and broader space. In this sense, electronic document's conversion into digital archives actually has the following control functions. First, control of the composition of digital archives from quantity to quality; second, effective maintenance of real condition of digital archival information through the application of multiple techniques; third, grant of legal evidence status to digital archival information in accordance with procedure; forth, sorting of digital archives in conversion process, laying a foundation for the organization and provision of digital archival information further.

Essential Conditions of Electronic Document's Conversion into Digital Archives. The conversion process must comply with general requirements of conversion from documents to archives. Additionally, in order to ensure the availability, accessibility and intelligibility of digital archives, relevant management measures must be taken in advance during the design of digital document management system, formation and application of digital document. 
During the design phase of digital document management system, in accordance with storage requirement of digital archives arising out of digital documents, it is essential to confirm the technology of saving digital documents, requirement of archiving, storage life and basic approach of sorting, as well as combine relevant management principles and practice with management system. [2]

During the formation of digital documents, strictly perform the function and requirement of digital document archiving specified in design phase, and supervise the formation of digital documents.

Most of formed digital documents are current ones during the application period. Once current digital documents come into force, maintenance of information security will become the primary task in this stage due to their characteristics of easy replicability and revision. Meanwhile, the information contained in digital documents that has original nature becomes an important condition to decide whether digital documents can be converted into digital archives.

Archiving means the "Pass" through Which Electronic Documents is converted into Digital Archives. In the process of conversion, "pass" is used for us to control the conversion. Unlike traditional paper document archiving, the archiving of digital document has its special contents.

On the issue of archiving scope, strong consideration should be given to software and hardware environment of computer, basic format of content of digital document, as well as relevant original data.

On the issue of archiving requirement, authenticity and integrity should be considered first, the second is to describe its software and hardware environment exactly, the third is to fully consider composite state of contents, storage carrier, software and hardware environment for digital documents. [3] On the issue of archiving method, the following may be adopted, namely saving final version of digital documents to be archived to storage carrier for compressed or back-up archiving.

\section{Dependent Law for the Formation of Digital Archives}

For any digital archives, when certain technology and equipment are used to record the information with long-term preservation value on storage carrier, it means digital archives can't separate with the technology and equipment for ever, but depends on this generating environment. People can only adopt it to record archives, and conduct reverse treatment for recovery and output to recognize the content. Specifically speaking, the dependence of digital archives on technology and equipment reflects on hardware, software and updating. [4]

Dependence of Digital Archives on Metadata. Metadata literally means data about data. For instance, the context and structural description of digital documents are metadata. For paper documents, metadata usually can't be reflected through its form. But metadata of digital documents must be specially attached to document information otherwise digital documents will not be recovered to original status. Furthermore, as the delivery and processing of paper documents can't separate with actual work of administration department and various procedures handled by working staff, metadata reflecting administrative background will naturally be recorded on documents. [5]In contrast, digital document is usually operated on the internet and metadata reflecting administrative background can't be shown on documents. If the metadata is not offered or supplemented, there will be problems with archiving, management and utilization of digital documents. Therefore, digital documents strongly depend on metadata during the formation, management and practical application. [6]

The Validity of Legal Evidence of Digital Archives is based on Originality of Information Content. During the formation and management of digital archives, information security technology is especially significant for maintaining the originality. From the application of information security technology, encryption technique, signing technique, message authentication technique, access control technique and write-protection technique have been applied in the management to various degrees. The authenticity, integrity and security of digital archives can be recognized through reverse 
treatment, recovery and output by use of the above-mentioned technology. Dependence of digital archives on technology and equipment mainly reflects in hardware, software and updating. [7]

Dependence of Digital Archives on Relevant Scientific Management Measures. In every link of the formation, storage and utilization of digital archives, information can be altered and lost possibly. Even perfect information security technology is available, corresponding management measures are also required to ensure the implementation. It is necessary to carry out whole process management of digital archives during the formation and management course. According to existing achievements, dependence of digital archives on management measures is focused on strengthening the management of digital document production and staffs, establishing the system for whole process management of digital documents and recording system for digital document management. [8]

\section{Virtualized Law for the Formation of Digital Archives}

Formation of paper archives generally takes the possession of archives department on paper archives as basic feature. Besides normal possession and management of digital archives, the formation of digital archives make the department have another mode of archives management, namely taking access of digital archival information as basic feature. Possession means an action of collecting tangible archive media for accumulation and utilization. While access refers to remotely search, collect and utilize archival information saved in each department individually, and it doesn't focus on a specific archive media. The access-centered variation trend during the formation and management of digital archives can be called virtualization which reflects in non-entity achieves of digital documents. [9]

As the information of digital documents has the feature of separating with original carrier, media or network archiving (also can be called information or non-entity archiving) can be both implemented at the pass of archiving when digital documents are converted into digital archives. Although a lot of security risk exists in archival information network, non-entity archiving of digital documents have already become possible and this method is very convenient. In case that related technology can guarantee the security of network archiving of digital documents, this method will be widely spread soon. There will be an orderly information space after digital archives which is formed from network archiving is organized. Compared with digital archives formed from paper archives and media archiving, digital archives usually shows intangible in the form. But it should be noted that this kind of non-entity archiving only means intangible carrier is adopted more in the formation of digital documents and processing department transferring them to archives management department, but doesn't stand for the nonexistence of carrier for digital archives. [10]

\section{Advantage and Necessity for Digital Conversion of Teacher's Professional Archives}

Teacher's professional archives has the potential of objective reliability and historical retrospective feature due to it's inhere attribute of originality and recording nature. The archive makes complete record and storage of development and growth of every teacher and has the potential for providing multi-dimension information service to related investigation of teacher's problems.

Development and Utilization of Information on Teacher's Learning-origin Structure. Learning-origin structure refers to structural and differential characteristics of teachers in graduated collage, school of thought, work and life. It is an important index of studying teaching staffs, as well as significant information content and potential service function in teacher's professional archives.

Employing units hope that their teachers have good learning-origin structure, talents of different college types, school of thought and regions are accompanied with reasonable arrangement in order to realize complementary advantages in cognitive structure, occupational character and academic feature, and create a learning-origin atmosphere of multi-idea and co-evolution; to avoid the recession of teaching quality due to single staff structure, it is required to develop original and comprehensive empirical materials from dimension development archives of learning-origin structure, divide into different categories and specifically study the development and change characters of graduates from 
different colleges on work to emphasize features and fill the gap; broadly study the correlation and causality between overall level and learning-origin structure in different development stages of teaching staffs; comparatively study which college's graduates are more welcomed by students, as well as the cause and effect. In this way, the school will have the initiative and scientific basis in receiving new teachers. Research on the performance of graduates in employing units can provide effective feedback information to enhance the level of running a school and quality of education. In qualitative talent evaluation, non-scientific bias is deeply rooted. On the one hand, teacher group have psychological obstacle in establishing their education authority because almost all of teachers are institutional authority in each field. On the other hand, deep-rooted prejudice and bias are significant reflection of social exchange relation, influencing people's judgment on objects, right or wrong, likes and dislikes. Only when we are rooted in original and recording professional archives and operate through scientific process, we can overcome non-scientific psychological obstacle in a certain degree. Otherwise the conclusions will be vague and general, just like comments left by some class teachers, they are meaningless, conventional, even wrong.

Researches made by the supply and demand sides who have different angles but consistent objective will link information about learning-origin structure of teachers with tracking survey on normal college students, as well as provide a practical route to requirement of Communication on Pre-career and Post-career Training (issued by State Education Commission) on reforming school-running system of normal colleges and schools.

Information Development of Discipline and Education Background and Research of Advantaged Discipline Construction. Discipline and education background structure refer to characteristics of teacher's teaching level and academic specialties composition in a certain discipline. It is the basic condition for advantaged discipline construction, as well as important information content and potential service contained in teacher's professional archives. School competition in future mainly shows in advantaged characteristics and characteristic advantages. While the characteristics and advantages are usually reflected in academic leaders of certain disciplines. In a sense, construction of advantaged disciplines is the lifeline of school running in future.

The problem focuses on which schools can have rights of academic control in municipal, provincial and national level. For this complicated system project, one of its fundamental conditions and core issues is to strengthen the development and research on discipline and education background structure information contained in teacher's professional archives. From a macro viewpoint, collect the information reflecting integrated academic level of school in the archives to determine which disciplines can be recommend as advantageous candidates; dig for the information about history, present situation and future of several disciplines, make overall textual research on disciplines with excellent conditions of education background structure (or condition of culture); further analyze professional capacity, academic specialties and potential of each teacher to determine the discipline leader (developing object) or the one to be introduced.

Information Development of Age Structure in Echelon Series and Research on New-century Talent Project. Age structure in echelon series refers to the quantity, proportion and characteristics of old, middle-aged and young teachers in the team or in academic echelon. It is the fundamental research for new-century talent project, important information resource and potential service function contained in teacher's professional archives.

The consolidation and exploitation of academic position of normal colleges and schools in future largely depends on the emphasis and construction level of talent project today, depends on fundamental research of age structure information in archives. Using Shandong province as an example, its talent echelon structure shows polarization trend, one is aging problem, there are more older teachers having senior professional post, but not working at the front line; the second is younger tendency, more young teachers work in the third echelon, but only a few of them have opportunity to engage in front-line teaching work, or obtain senior professional post; this third is fewer middle-aged 
teachers, there are fewer middle-aged core teachers with high teaching level. Therefore, cultivating young teachers as the backbone has become the top priority of talent project.

Dominant Information Development and Digital Conversion of Achievements. Teacher's professional archives, especially the achievements, belongs to historical epitome in the development and growth of the team and individual. It is a reflection of management performance crystallization of personal effort and value, as well as special course influencing students Archives is not only the memory device recording teacher's working achievements, but also display device showing them. It needs us to exploit valuable information behind it and use the information in communication $\mathrm{A}$ special archives about core teachers, teaching and scientific research experts at school, municipal and provincial levels may be established to play a leading role. Literature from teacher's working achievements may be edited and communicated between teachers and students via the internet, moving closed environment towards an open palace.

\section{References}

[1] X.Wang, Generation and Understandability of Electronic Archives, Journal of Heilongjiang Local Chronicles. 11 (2015) p. 150(In Chinese)

[2] L. Luan, Post-Evaluation Research of The Electronic Document and Record Management System (MS., Beijing University of Posts and Telecommunications, China 2013) p.17 (In Chinese)

[3] ]J. X. Ping, Analysis on Sorting and Filing of Electronic Documents, Journal of Heilongjiang Local Chronicles. 7 (2011) p.61-62(In Chinese)

[4] Y.Z.Mei, Study on the Electronic Documental Archives Management at Schools, Journal of Popular Literature and Art. 11 (2011) p. 276(In Chinese)

[5] Y.L.Kong, The Preservation and Protection of Electronic Archives, Journal of Chifeng Xueyuan (Natural Science Edition). 6 (2009) p.146-147(In Chinese)

[6] M.Li, H.M.Li, Process Design of Virtual Achives in the Era of Electronic Document, Journal of Taiwan World. 16 (2010) p.3-4(In Chinese)

[7] S.J.Li, X.Shi, Management of Foreign Affairs Archives in Colleges and Universities in the Era of Electronic Archives, Journal of Lantai World. 3 (2007) p.43-44(In Chinese)

[8] H.Y.Cui, The Recognition and Mantainance of Primitiveness of Electronic Documents [J], Archives and Establishment. 10 (2006) p.22-24(In Chinese)

[9] G.Y.Chen, The Virtualization Trend of Archives Arrangement, Journal of Hubei Archives. 6 (2007) p.15-18(In Chinese)

[10] B.Hu, Exploration on the Coexistence and Complementary of Virtual File and Entity File, Journal of Heilongjiang Archives. 3 (2013) p.16 (In Chinese) 